\title{
The development of the EULAR-OMERACT rheumatoid arthritis MRI reference image atlas
}

\author{
P Bird, P Conaghan, B Ejbierg, F McQueen, M Lassere, C Peterfy, J Edmonds, R Shnier, \\ $P$ O'Connor, E Haavardsholm, P Emery, $H$ Genant, M Østergaard
}

Ann Rheum Dis 2005;64(Suppl I):i8-i10. doi: 10.1136/ard.2004.031807

Based on a previously developed rheumatoid arthritis MRI scoring system (OMERACT 2002 RAMRIS), the development team agreed which joints, MRI features, MRI sequences, and image planes would best illustrate the scoring system in an atlas. After collecting representative examples for all grades for each abnormality (synovitis, bone oedema, and bone erosion), the team met for a three day period to review the images and choose by consensus the most illustrative set for each feature, site, and grade. A predefined subset of images (for example, for erosion-all coronal slices through the bone) was extracted. These images were then re-read by the group at a different time point to confirm the scores originally assigned. Finally, all selected images were photographed and formatted by one centre and distributed to all readers for final approval.
See end of article for authors' affiliations

Correspondence to: Prof $M \varnothing$ stergaard, Department of Rheumatology, Copenhagen Úniversity Hospital at Hvidovre, Kettegaard alle 30, DK2650 Hvidovre, Denmark; mo@dadlnet.dk
$\mathrm{T}$ he aim of developing the reference film atlas was to create a new tool for standardised assessment of rheumatoid arthritis (RA) joints, based on the OMERACT 2002 rheumatoid arthritis MRI scoring system (OMERACT RAMRIS), ${ }^{1}$ which would allow semiquantitative scoring of MR image sets for inflammatory and destructive changes guided by standard reference images. This article describes the process of development of the atlas.

\section{AGREEMENT ON IMPORTANT FEATURES, DEFINITIONS, AND SCORING SYSTEM}

Magnetic resonance imaging (MRI) definitions of important RA joint pathologies and a core set of basic MRI sequences to be used for imaging of the RA joint have previously been suggested by the OMERACT MRI in RA group. ${ }^{1}$ Furthermore, based on a series of studies, ${ }^{2-4}$ an RA MRI scoring system (OMERACT 2002 RAMRIS) for evaluation of inflammatory and destructive changes in RA hands and wrists has been developed (see the previous paper ${ }^{5}$ in this supplement for details).

Following a decision of the OMERACT MRI group to develop a standard reference image set (atlas) based on the OMERACT 2002 RAMRIS, it was agreed that the example images should cover the features, definitions, and scoring system of the RAMRIS. The atlas should allow scoring of wrist and metacarpophalangeal (MCP) joints for the commonly described MRI abnormalities of synovitis, bone oedema, and bone erosion.

\section{COLLECTION OF THE IMAGE EXAMPLES}

After agreement on the MRI features to be represented in the atlas, one of the co-chairs of the group allocated the task of finding representative examples to four centres involved in the creation of the atlas (Sydney, Copenhagen, Leeds, and Auckland) (table 1). The group recognised that differences between magnet strengths and sequence protocols at the contributing centres could affect image standardisation. Therefore, during selection of images for the atlas, the group tried to provide examples for each region and pathology from a single centre. Where this was not possible, a secondary centre contributed images. All films provided were on standard radiographic film.

\section{LIMITING OF EXAMPLES TO SELECTED AREAS}

To make the development and publication of the atlas feasible, it was necessary to limit the examples to certain anatomical areas (rather than every single grade of every abnormality at all sites). The selected examples for the wrist are listed in table 1. It was considered important and feasible to illustrate synovitis of all grades, that is, $0-3$, in each of the three wrist areas scored for synovitis in the RAMRIS. The four metacarpophalangeal (MCP) joints were considered sufficiently uniform for one series of illustrations of MCP synovitis grades to give adequate guidance for scoring of all MCP joints.

It was decided that an example from both the lower and higher ends of the range of each grade of synovitis should be presented, in order to provide a range of synovitis examples fulfilling a particular score category. Providing examples of every grade of pathology for every bone in the wrist and every bone in the MCP joints was considered unnecessary and excessive because this would have required the provision of 100 examples for wrist bone erosion alone. Instead, five bones in the wrist were selected as examples, and several grades of pathology are illustrated for each.

One series of image examples was considered sufficient to allow scoring the bone areas of all the MCP joints. The lower bone erosion grades-

Abbreviations: EULAR, European League Against Rheumatism; MCP, metacarpophalangeal (joint); MRI, magnetic resonance imaging; RA, rheumatoid arthritis 
Table 1 The example images requested for the EULAR-OMERACT rheumatoid arthritis MRI reference image atlas and the allocated collection centres

\begin{tabular}{|c|c|c|c|c|c|c|}
\hline \multirow[b]{2}{*}{ Selection } & \multicolumn{2}{|c|}{ Synovitis } & \multicolumn{2}{|c|}{ Bone oedema } & \multicolumn{2}{|c|}{ Bone erosion } \\
\hline & MCP joint & Wrist & MCP joint & Wrist & MCP joint & Wrist \\
\hline Areas & Second or third & $\begin{array}{l}\text { Distal radioulnar } \\
\text { Radiocarpal } \\
\text { Intercarpal-CMC }\end{array}$ & $\begin{array}{l}\text { Metacarpal head } \\
\text { Phalangeal base }\end{array}$ & $\begin{array}{c}\text { Radius } \\
\text { Scaphoid } \\
\text { Lunate } \\
\text { Capitate } \\
\text { Third metacarpal base }\end{array}$ & $\begin{array}{l}\text { Metacarpal head } \\
\text { Phalangeal base }\end{array}$ & $\begin{array}{l}\text { Radius } \\
\text { Scaphoid } \\
\text { Lunate } \\
\text { Capitate } \\
\text { Second or third } \\
\text { metacarpal base }\end{array}$ \\
\hline $\begin{array}{l}\text { Grades } \\
\text { MRI sequences }\end{array}$ & \multicolumn{2}{|c|}{ All (0-3) } & \multicolumn{2}{|c|}{ All (0-3) } & \multicolumn{2}{|c|}{ Grade $0-3+$ examples of higher grades } \\
\hline For scoring & \multirow{2}{*}{\multicolumn{2}{|c|}{$\begin{array}{c}\text { Axial precontrast } \\
\text { and postcontrast Tl weighted } \\
\text { Coronal precontrast and postcontrast } \\
\text { Tl weighted }\end{array}$}} & \multicolumn{2}{|c|}{ Coronal T2 weighted fat saturated or STIR } & \multicolumn{2}{|c|}{ Coronal $\mathrm{Tl}$ weighted } \\
\hline Additional & & & & - & Axial Tl weighted ( & onfirm cortical break) \\
\hline $\begin{array}{l}\text { Centre allocation } \\
\text { (primary/ } \\
\text { secondary) }\end{array}$ & Leeds/Sydney & $\begin{array}{l}\text { Copenhagen/ } \\
\text { Sydney }\end{array}$ & Leeds/Sydney & Auckland/Copenhagen & Leeds/Sydney & Copenhagen/Auckland \\
\hline $\begin{array}{l}\text { Origin of final } \\
\text { atlas images* }\end{array}$ & Leeds & $\begin{array}{l}\text { Copenhagen, } \\
\text { Oslo }\end{array}$ & Leeds & $\begin{array}{l}\text { Copenhagen, Leeds, } \\
\text { Oslo }\end{array}$ & Leeds, Sydney & Copenhagen, Auckland \\
\hline
\end{tabular}

that is, $0-3$ - corresponding to an erosion volume of $0-39 \%$ of the original bone, are always represented. In addition, selected examples of scores $4-10$ are provided for each bone. $^{67}$

Bone oedema is illustrated in the same bones (table 1) and all grades (that is, $0-3$ ) are illustrated. However, it was not possible to find examples of grade 3 oedema at all sites (in the radius, scaphoid, and lunate).

\section{INITIAL MRI INTERPRETATION AND CONSENSUS}

The group met in Sydney, Australia, in April 2003 for a three day period to review the MRI films. Six readers representing four MRI centres (Auckland, Copenhagen, Leeds, and Sydney) reviewed the films together. Four of the six readers had previously taken part (as MRI readers) in the OMERACT and/or EULAR MRI scoring trials..$^{2-4} 9{ }^{10}$ As mentioned before, scoring was undertaken using the OMERACT 2002 RAMRIS.

For each type of lesion, the primary centre provided three examples for each grade in a selected bone. For each feature, site, and grade, consensus was reached and the most representative film set was chosen for inclusion in the atlas. All readers read all film sets at the same time with consensus reached by discussion. Selection of images for the atlas of bone oedema in the wrist bones was postponed due to the lack of optimal images (see below).

\section{SELECTION OF SEQUENCE TYPE, IMAGE PLANES, AND SUBSET OF IMAGES}

After identification of the most representative set of films for each feature and grade, a subset of images was chosen to illustrate the grade in the atlas (tables 1 and 2). The selected sequence types and image planes represent the group's consensus opinion about the best possible image type for scoring this particular feature.

For synovitis, the axial image plane was selected, as it is perpendicular to the main orientation of the synovium and therefore less prone to partial volume artefacts. A short series of axial precontrast and postcontrast $\mathrm{Tl}$ weighted images was chosen, as several images are needed to determine the distribution of the synovitis.

For each grade of MCP and wrist erosion, all coronal precontrast $\mathrm{Tl}$ weighted slices through the bone were selected for presentation, in order to allow performing the scoring procedure, that is, calculation of the percentage of the bone volume occupied by erosion. In addition, an axial image was chosen to confirm that erosion was visible in two planes, as required by definition. ${ }^{5}$

The group agreed that coronal T2 weighted fat saturated or short tau inversion recovery (STIR) sequences images provided the most sensitive visualisation and scoring of bone oedema. In the wrist, however, such images were only

Table 2 The most frequently used MRI sequence parameters for visualisation of synovitis, bone oedema, and bone erosion in the centres contributing reference images of the individual features for the atlas

\begin{tabular}{|c|c|c|c|c|c|c|c|c|c|c|c|}
\hline & Centre* & $\begin{array}{l}\text { Field strength, } \\
\text { Magnet }\end{array}$ & Sequence & TE (ms) & TR (ms) & TI (ms) & Acq. & FOV $(\mathrm{mm})$ & Matrix & ST $(\mathrm{mm})$ & Gap (mm) \\
\hline \multirow[t]{3}{*}{ Synovitis } & Copenhagen & 1.0 T Siemens & TI SE & 15 & 600 & - & 2 & $109 \times 145$ & $192 \times 256$ & 3 & 0 \\
\hline & Leeds & 1.5 T Philips & TI SE & 20 & 485 & - & 4 & $100 \times 50$ & $205 \times 256$ & 1.5 & 1.0 \\
\hline & Oslo & 1.5 T Gen. El. & TI SE & 13 & 420 & - & 2 & $100 \times 100$ & $512 \times 320$ & 3 & 0.5 \\
\hline \multirow[t]{4}{*}{ Oedema } & Leeds & 1.5 T Philips & T2 SPIR & 100 & 2000 & 180 & 3 & $100 \times 100$ & $202 \times 256$ & 2.0 & 0.2 \\
\hline & Oslo & 1.5 T Gen. El. & STIR & 12 & 3760 & 150 & 2 & $100 \times 100$ & $288 \times 192$ & 2.5 & 0.5 \\
\hline & Copenhagen & 1.0 T Siemens & STIR & 30 & 4500 & 150 & 3 & $145 \times 108$ & $256 \times 182$ & 3.0 & 0.0 \\
\hline & Sydney & 1.5 T Gen. El. & TIRM & 30 & 3289 & 130 & 2 & $130 \times 130$ & $217 \times 256$ & 3.0 & 0.3 \\
\hline \multirow{3}{*}{ Erosion } & Copenhagen & 0.2 T Esaote & T1 3D GE† & 12 & 30 & - & 1 & $140 \times 140$ & $192 \times 160$ & 2.0 & 0.0 \\
\hline & Leeds & 1.5 T Philips & TI SE & 20 & 485 & - & 4 & $100 \times 50$ & $205 \times 356$ & 1.5 & 1.0 \\
\hline & Auckland & 1.5 T Gen. El. & TI SE & 14 & 680 & - & 1 & $80 \times 80$ & $256 \times 192$ & 3.0 & 1.0 \\
\hline
\end{tabular}

${ }^{*}$ Centres are listed ordered after the number of presented images of this particular type of pathology.

$\mathrm{TT} 1$ weighted three dimensional gradient echo with subsequent multiplanar reconstruction. The flip angle was $65^{\circ}$.

Acq, number of acquisitions; FOV, field of view; GE, gradient echo; Gen. El., General Electrics; SPIR, spectral prepulse inversion recovery; ST, slice thickness; STIR,

short tau inversion recovery; TI SE, Tl weighted spin echo; TE, echo time; TI, inversion time; TIRM, turbo inversion recovery magnitude; TR, repetition time. 
available in the axial plane at the first meeting. As a consequence, at a second round of image viewing, consensus was reached for coronal wrist bone oedema images. Candidate images for this second round were collected in Copenhagen, Leeds, and Oslo. During the same process, a few of the original synovitis illustrations were replaced with new selections, considered to be of a better quality and/or more representative for the upper or lower end of this particular grade of synovitis.

Each of the selected images was marked and recorded.

\section{SECOND READING OF ALL IMAGES}

Following completion of the initial selection of images, all images were re-read by all five observers to confirm the feature and grade allocated on initial scoring. Agreement was reached by consensus as per the initial reading. These selections were marked and recorded.

\section{PREPARATION OF IMAGES}

All images were photographed, cropped, and formatted at the Copenhagen University Hospital at Hvidovre (MØ, BE). Subsequently, the images were distributed to all readers for approval prior to publication.

\section{FINAL PROCEDURES}

In June 2003, the group assembled to review the photographed examples, to clarify any issues relating to the image examples, and to discuss these issues with other members of the OMERACT MRI RA group (CP, HG, PE) who had been unable to attend the meeting in Sydney. Alternative image sets were available in case of need for revisions. Consensus was reached regarding the presentation of the image examples, including page set up.

Even though numerous new image sets were reviewed, a sufficient number of candidate wrist bone oedema images were still not available. Between July 2003 and April 2004, the remaining wrist joint bone oedema images were collected. At a series of group meetings at the OMERACT 7 conference at Asilomar, CA, in May 2004, the final image selections and revisions were made by consensus, following procedures as described above. In total, 1002 images were included (see table 1). ${ }^{6-8}$

Between June and August 2004, the final formatting, circulation, and approval by all members were completed. Finally, the atlas was submitted, with images prearranged page by page, to the Annals of the Rheumatic Diseases, with financial support from EULAR.

\section{ACKNOWLEDGEMENTS}

The European League Against Rheumatism (EULAR) is acknowledged for financial support of the publication of this atlas.

\section{Authors' affiliations}

P Bird, Department of Rheumatology, St George Hospital, University of NSW, Sydney, Australia
P Conaghan, Academic Unit of Musculoskeletal Disease, University of Leeds, Leeds, UK

B Ejbjerg, Departments of Rheumatology, Radiology, and MRI, Copenhagen University Hospital at Hvidovre, Copenhagen, Denmark

F McQueen, Department of Molecular Medicine and Pathology, Faculty of Medicine and Health Sciences, University of Auckland, Auckland,

New Zealand

M Lassere, Department of Rheumatology, St George Hospital, University of NSW, Sydney, Australia

C Peterfy, Synarc Inc, San Francisco, CA, USA

J Edmonds, Department of Rheumatology, St George Hospital, University of NSW, Sydney, Australia

R Shnier, Department of Diagnostic Imaging, Mayne Nickless, Sydney, Australia

P O'Connor, Department of Radiology, Leeds General Infirmary, Leeds, UK

E A Haavardsholm, Department of Rheumatology, Diakonhjemmet Hospital, University of Oslo, Oslo, Norway

P Emery, Academic Unit of Musculoskeletal Disease, University of Leeds, Leeds, UK

H Genant, Department of Radiology, University of California at San Francisco, San Francisco, CA, USA

M Østergaard, Departments of Rheumatology, Copenhagen University Hospitals at Herlev and Hvidovre, Copenhagen, Denmark

\section{REFERENCES}

1 Østergaard M, Peterfy C, Conaghan P, McQueen F, Bird P, Ejbjerg B, et al. OMERACT rheumatoid arthritis magnetic resonance imaging studies. Core set of MRI acquisitions, joint pathology definitions, and the OMERACT RA-MRI scoring system. J Rheumatol 2003;30:1385-6.

2 Østergaard M, Klarlund M, Lassere M, Conaghan P, Peterfy C, McQueen F, et al. Interreader agreement in the assessment of magnetic resonance images of rheumatoid arthritis wrist and finger joints - an international multicenter study. J Rheumatol 2001;28:1143-50.

3 Conaghan P, Lassere M, Østergaard M, Peterfy C, McQueen F, O'Connor P, et al. OMERACT rheumatoid arthritis magnetic resonance imaging studies. Exercise 4: an international multicenter longitudinal study using the RA-MRI Score. J Rheumatol 2003;30:1376-9.

4 Lassere M, McQueen F, Østergaard M, Conaghan P, Shnier R, Peterfy C, et al. OMERACT rheumatoid arthritis magnetic resonance imaging studies. Exercise 3: an international multicenter reliability study using the RA-MRI Score. J Rheumatol 2003:30:1366-75.

5 Østergaard M, Edmonds J, McQueen F, Peterfy C, Lassere M, Ejbjerg B, et al. An introduction to the EULAR-OMERACT rheumatoid arthritis MRI reference film atlas. Ann Rheum Dis 2005;65(suppl I):i3-7.

6 Conaghan P, Bird P, Ejbjerg B, O'Connor P, McQueen F, Peterfy C, et al. The EULAR-OMERACT rheumatoid arthritis MRI reference image atlas: the metacarpophalangeal joints. Ann Rheum Dis 2005;65(suppl I):i1 1-i21.

7 Ejbjerg B, McQueen F, Lassere M, Haavardsholm E, Conaghan P, O'Connor P, et al. The EULAR-OMERACT rheumatoid arthritis MRI reference image atlas: the wrist joint. Ann Rheum Dis 2005;65(suppl I):i23-47

8 McQueen F, Østergaard M, Peterfy C, Lassere M, Ejbjerg B, Bird P, et al. Pitfalls in MRI scoring of rheumatoid arthritis wrist and metacarpophalangeal joints. Ann Rheum Dis 2005;65(suppl I):i48-55.

9 O'Connor P, Østergaard M, Klarlund M, Peterfy C, Astin P, van der Heijde D, et al. Longitudinal evaluation of MRI scoring in rheumatoid arthritis - an international multicenter study of interreader agreement [abstract]. Arthritis Rheum $2001 ; 44$ (suppl):S315

10 Østergaard M, Conaghan P, O'Connor P, Ejbjerg B, Szkudlarek M, Peterfy C, et al. Reducing costs, duration and invasiveness of magnetic resonance imaging in rheumatoid arthritis by omitting intravenous gadolinium injection-does it affect assessments of synovitis, bone erosions and bone edema? [abstract]. Ann Rheum Dis 2003;62(suppl I):67. 